PontIFícIA UNIVERSIDADE CATÓLICA dO RIO DE JANEIRO

\title{
A Indústria 4.0 e as competências do século XXI sob a ótica dos universitários
}

\author{
Sabrina Silva Lima
}

Trabalho de Conclusão de Curso

Centro de CIÊnCIAS SOCIAIS - CCS

DEPARTAMENTO DE AdMINISTRAÇÃO

Graduação em Administração de Empresas 
Sabrina Silva Lima

A Indústria 4.0 e as competências do século XXI sob a ótica dos universitários

Trabalho de Conclusão de Curso

Trabalho de Conclusão de Curso, apresentado ao programa de graduação em Administração da PUC-Rio como requisito parcial para a obtenção do titulo de graduação em Administração.

Orientador(a) : Renata Kurtz

Rio de Janeiro

Novembro de 2019. 


\section{Agradecimentos}

A Deus, pois sem ele nada é possível.

A minha família, Tânia Cristina, Gilson Lopes Lima e Igor Lima, eles mostraramse presentes nos momentos mais precisos. Deram-me esperança quando estava desiludida, me proporcionaram energia enquanto estava abatida e me ofereceram paz em tempos de batalhas. Além de tudo, sempre acreditaram no meu potencial e na capacidade de ir em busca dos meus sonhos para torná-los realidade.

A minha orientadora, Renata Georgia Motta Kurtz por compartilhar seu amplo conhecimento e tempo contribuindo para meu desenvolvimento acadêmico e pessoal. Os meus mais sinceros agradecimentos pelo apoio fornecido durante o projeto.

A uma pessoa especial, Luis Cláudio que sempre esteve ao meu lado. Obrigada pelos incentivos e pelos bons momentos com o objetivo de me fazer feliz.

A pessoas excepcionais como minha vó Marlene e aos pequenos Jorge Henrique e Myrella.

A PUC-RIO, compreendo que a partir dela sou um ser humano muito melhor. Isso se tornou possível por ser composta por profissionais responsáveis e competentes. 


\section{Resumo}

Silva Lima, Sabrina. Indústria 4.0 e as competências do século XXI sob a ótica dos universitários. Rio de Janeiro, 2019. 41 p. Trabalho de Conclusão de Curso - Departamento de Administração. Pontifícia Universidade Católica do Rio de Janeiro.

O mercado de trabalho tem enfrentado diversas mudanças ao longo do tempo devido ao crescimento exponencial da tecnologia. Atualmente vive-se uma transformação digital na indústria sendo referenciada como uma nova revolução nomeada de Quarta Revolução Industrial ou Indústria 4.0 que foi procedida por três anteriores. Diante dos desafios sociais, econômicos e políticos gerados pela atual revolução, as organizações devem reavaliar sua estrutura e processo produtivo para acompanharem os avanços e consequentemente se mantes competitiva. Nesse sentido, percebe-se mudanças acerca do trabalho devido a interação homem e máquina. Diante do exposto, este trabalho se propõe a analisar os impactos causados pela Indústria 4.0 e as competências requeridas para os trabalhadores do século XXI.

Palavras-chave

Indústria 4.0, Competências do século XXI, Mercado de Trabalho, Profissionais 


\section{Abstract}

Silva Lima, Sabrina. Indústria 4.0 e as competências do século $\mathrm{XXI}$ sob a ótica dos universitários. Rio de Janeiro, 2019. 41 p. Trabalho de Conclusão de Curso - Departamento de Administração. Pontifícia Universidade Católica do Rio de Janeiro.

The job Market has faced several changes over time due to the exponential growth of technology. Currently there is a digital transformation in the industry being referred to as a new revolution named Fourth Industrial Revolution or Industry 4.0 that was procedes by three previous ones. Faced with the social, economic and political challenges generated by the current revolution, organizations must reassess their structure and production process to keep up with progress and thus remain competitive. In this sense, we notice changes about work due to the interaction between man and machine. Given the above, this paper aims to analyze the impacts caused by Industry 4.0 and the skills required for 21 st century workers.

Key-words

Industry 4.0, 21 st Century Skills, Labor Market, Professionals 


\section{Sumário}

1. O tema e o problema de estudo 1

1.1. Introdução ao tema e ao problema do estudo 1

1.2. Objetivo do estudo 1

1.3. Objetivos intermediário do estudo 4

1.4. Delimitação e foco do estudo 4

1.5. Relevância do estudo 4

2. Referencial Teórico 6

2.1. Indústria $4.0 \quad 6$

2.2. Impactos dos avanços tecnológicos $\quad 7$

2.3. Novos trabalhos e novas profissões 9

2.4. Desenvolvimento profissional na indústria $4.0 \quad 12$

3. Metodologia 17

$\begin{array}{lr}\text { 3.1. Tipo de pesquisa } & 17\end{array}$

3.2. Procedimentos e instrumentos de coleta de dados 18

3.3. Tratamento e análise dos dados 18

$\begin{array}{ll}\text { 3.4. Limitações do método } & 18\end{array}$

4. Apresentação e análise dos resultados 20

4.1. Conhecimento sobre a indústria 4.0

4.1.1. Aspectos positivos da indústria $4.0 \quad 21$

4.1.1.1. Impactos para o trabalho 21

4.1.1.2. Impactos para as empresas $\quad 22$

4.1.1.3. Impactos para os funcionários 23

4.1.2. Aspectos negativos da indústria $4.0 \quad 24$

4.1.2.1 Competividade no mercado de trabalho 25

4.1.2.2 Mudanças no desenvolvimento do profissional 26

4.2. Competências para o século XXI 28

4.2.1 Competências no presente e no futuro no mundo do trabalho 29 
7. Anexo

\section{Lista de figuras}

Figura 1: Competências e seus respectivos domínios

\section{Lista de Tabelas}

Tabela 1: Profissões mais e menos sujeitas à automação

Tabela 2: Habilidades e competências exigidas para o século XXI

15

Tabela 3: Referências demográficas dos entrevistados

\section{Lista de gráficos}

Gráfico 1: Impacto das tecnologias de inteligência artificial nos empregos do mundo até 2025 


\section{0 tema e o problema de estudo}

\subsection{Introdução ao tema e ao problema do estudo}

A história do trabalho sofreu importantes transformações ao longo dos séculos. Mais recentemente, importantes mudanças ocorreram a partir da Revolução Industrial, iniciada na Inglaterra em meados do século XVIII, até a Revolução Industrial 4.0, com início no século atual. Os artesãos deram espaço aos atuais integrantes de grandes instituições que têm por objetivo alcançar resultados planejados através da inteligência humana e artificial (Exame, 2019). Mediante aos grandes volumes de informações fornecidos pelos algoritmos, as organizações visam atender às exigências de um mercado globalizado, altamente competitivo e complexo. A partir deste cenário, as relações trabalhistas mudaram e se adaptaram às condições e necessidades das pessoas ao longo dos anos.

As revoluções industriais foram marcadas pelo desenvolvimento tecnológico. De acordo com a pesquisa Worth Global Style Network (WGSN) e Linkedln (2019), a máquina a vapor foi determinante para a primeira revolução industrial no final do século dezessete. Já no final do século dezenove, as indústrias químicas de aço, petróleo e elétrica construíram a segunda revolução. A terceira teve como grandes marcos a ampliação das fontes de energia no mundo e a robótica. E a quarta se caracteriza pela convergência digital, física e biológica que são feitas com tecnologias como a nuvem, a internet das coisas, big data, inteligência artificial e biotecnologia, basicamente.

Dentre as maiores organizações, conforme a pesquisa da BrandZ Kantar e o grupo de mídia WPP em 2019, a marca Amazon foi avaliada em US\$315,5 bilhões, contra US\$309,5 bilhões da Apple. Em terceiro, aparece o Google com valor de US\$ 309 bilhões. Neste contexto, parece que as empresas de tecnologia hoje dominam o mundo dos negócios.

O ambiente gerencial tem sofrido mudanças profundas, inclusive em suas estruturas devido à inserção de novas tecnologias nas organizações; algoritmos 
e automação por meio do Aprendizado de Máquina tornaram-se cada vez mais comuns, principalmente devido à competição entre as firmas por aumentar a produção e reduzir custos (CREWS, 2019). Essa afirmação aponta uma reflexão para outras mudanças como a estratégia e o modelo de negócios. Nesse sentido, os gestores precisam estar cientes dessa tendência de automação, dos desafios que ela proporciona e de como suas organizações podem se beneficiar da implementação desses sistemas.

Nos últimos tempos, a automação tornou-se uma realidade global que causa uma certa apreensão nos empregados. O principal ponto é a possibilidade do desemprego em massa nos próximos períodos devido às tecnologias oriundas do aprendizado da máquina (AM) (HERNANDEZ-PERDOMO, GUNEY E ROCCO, 2018).

Entretanto, segundo estudo da Gartner em 2017, se por um lado a inteligência artificial elimina 1,8 milhões de empregos, por outro vai criar 2,3 milhões em 2020. Esta pesquisa sugere que a inteligência artificial eliminará milhões de posições de nível médio e baixo, porém criará milhões de novas posições que precisará de habilidades altamente qualificadas e gerenciamento (GARTNER, 2017).

De acordo com um levantamento em 2018 da Comissão Econômica para a América Latina e Caribe (CEPAL), 65\% de todas as crianças do planeta que entram hoje na escola primária terão empregos que ainda não existem. Ou seja, as mudanças são inevitáveis, o mercado ainda vai mudar muito para rumos ainda não conhecidos. Por isso, parece que a maneira ideal para se preparar para este novo mercado é estar atento às transformações que estão acontecendo agora e reconhecer nelas os embriões desse futuro. Segundo Bárnea (2018), as conquistas da ciência "representam uma oportunidade" para a criação de novos empregos, mas apenas se houver um novo pacto social entre os governos, setor privado, academia e a juventude, a fim de mudar os sistemas educativos e a forma como os países enfrentam a questões tecnológicas. É preciso, portanto, ajudar os jovens a compreender as novas tecnologias e capacitá-los nesse novo contexto.

Ademais, as mudanças do mercado de trabalho impactam novos desafios sobre como formar os profissionais desenvolvendo as competências necessárias e alinhá-las com as expectativas dos jovens. A educação é o princípio de tudo. Conforme uma pesquisa realizada entre a rede social Linkedln e a WGSN em 2019, escolas e startups de educação adotam estratégias inovadoras e revolucionárias. Os estudantes devem ser preparados por novas maneiras para 
tecnologias que ainda precisam ser inventadas. Logo, o currículo escolar está incluindo ferramentas e metodologias pouco ortodoxas, como gamificação e design thinking, que devem se tornar conceitos educacionais permanentes na grade das escolas. Da mesma forma, a prática de mindfullness passa a integrar a grade de atividades fundamentais, afetando presença e concentração para um melhor aprendizado (WGSN e Linkedln, 2019).

A partir deste novo cenário tecnológico, uma pesquisa encomendada pela Dell Technologies e realizada pela Dimensional Research em 2018 aponta que a maioria dos jovens brasileiros (85\%), entre 16 e 23 anos, desejam trabalhar com o desenvolvimento ou implementação de novas tecnologias. O estudo evidencia que o público analisado aposta que os novos recursos e o volume de dados analíticos oferecidos pela tecnologia permitirão ambiente de trabalho mais justos e igualitários, irá prevenir a discriminação baseada em sexo, raça ou idade.

Com tantas transformações tecnológicas, os desafios parecem ser muitas vezes mais humanos do que técnicos. Nestas circunstâncias, é possível identificar que, quanto maior a utilização de tecnologias no ambiente profissional, mais valorizados são as habilidades humanas.

A citação de Rollings ilustra essa ideia:

\footnotetext{
"A tecnologia pode assumir tarefas repetitivas e mundanas, liberando humanos para outras atividades, mas a simbiose de humanos com ela será mais sutil e exigirá reinvestimento e reinvenção, em vez de simplesmente automatizar as práticas existentes" (Mike Rollings, 2019, p. 35).
}

Neste contexto, este estudo pretendeu investigar as percepções dos estudantes universitários formandos sobre as novas competências requeridas pelo mercado de trabalho e as respectivas formas de desenvolvê-las.

\subsection{Objetivo do Estudo}

Em face da realidade mencionada, o objetivo deste estudo é investigar a percepção dos estudantes universitários formandos sobre os impactos causados pela Indústria 4.0, as competências requeridas para o mercado de trabalho atual (conhecidas como competências do século XXI) e sobre seu desenvolvimento para as respectivas competências. 


\subsection{Objetivos intermediários do estudo}

Para se atingir o objetivo final proposto neste estudo, será preciso compreender os objetivos intermediários destacados abaixo:

> Identificar as mudanças que os avanços tecnológicos geraram no trabalho exercido pelos empregados nas organizações;

> Identificar as principais competências exigidas pelo mercado de trabalho no século XXI;

> Investigar as expectativas dos formandos sobre as competências necessárias para o mercado de trabalho;

> Investigar a percepção dos formandos sobre o desenvolvimento das respectivas competências.

\subsection{Delimitação e foco do estudo}

Este estudo está delimitado a alunos de graduação do curso de administração a partir do sétimo período matriculados em uma universidade particular do Rio de Janeiro no ano de 2019. Por meio da pesquisa serão analisados os pontos de vista do público estudado em relação aos desafios contemporâneos referente ao mercado de trabalho na atual Quarta Revolução Industrial.

Assim, esse estudo não pretende implementar um modelo informativo sobre as melhores profissões do século XXI. Não é objetivo desta pesquisa estabelecer medidas que o público estudado deve seguir. Não é foco deste trabalho fazer um acompanhamento dos jovens universitários e recémformados.

\subsection{Relevância do estudo}

Com relação à relevância acadêmica, o estudo pretende colaborar com a expansão de conhecimentos das competências requeridas para o mercado de trabalho no século XXI. Além disso, compartilhar a percepção dos estudantes sobre o seu desenvolvimento diante das competências exigidas pelo mercado de trabalho. Desse modo, os resultados poderão contribuir através de informações adicionais relevantes para outros estudos e pesquisas do tema. 
No que se refere a relevância profissional, abordar essa temática é um meio de colaborar indicando as novas formas de desenvolvimento das competências solicitadas no século XXI. Assim, as universidades terão um feedback a respeito do assunto e podem pensar em ações para desenvolver as competências nos próximos alunos. Os universitários poderão se beneficiar através das informações contidas nesta pesquisa para se destacar no processo de estágio ou trainee. Por fim, os resultados do estudo contribuem para o aprimoramento da relação dos jovens, Instituições e a Indústria 4.0. 


\section{Referencial teórico}

\subsection{Indústria 4.0}

Mudanças profundas ocorreram ao longo das décadas devido ao avanço das inovações tecnológicas, proporcionando desdobramentos nos âmbitos econômicos, sociais e políticos. Este conjunto de inovações e evoluções é nomeado como uma revolução industrial (DOMBROWSKI, WAGNER, 2014).

O conceito de indústria 4.0 foi utilizado em 2011 na Feira de Hannover, um evento de tecnologia industrial na Alemanha para definir o que seria a Quarta Revolução Industrial (DRATH; HORCH, 2014), vindo após três revoluções que resultaram da mecanização, eletricidade e das tecnologias da informação (KAGERMANN; WAHLTER; HELBIG, 2013).

De acordo com Lydon, a indústria 4.0 tem por objetivo proporcionar melhorias aos processos de fabricação em um conjunto de dimensões como eficiência, capacidade de resposta e a capacidade de satisfazer as necessidades individuais dos clientes em tempo hábil (LYDON, 2015). O progresso tecnológico fomentou a produtividade industrial, reduzindo os custos de produção e fornecendo soluções eficazes para atender aos clientes com qualidade, velocidade e melhor custo/benefícios (CHENG ET AL., 2015). Nessa abordagem, as máquinas usam auto-otimização, auto-configuração e inteligência artificial para completar tarefas complexas, a fim de proporcionar eficiências de custo muito superiores e bens ou serviços de melhor qualidade (BAHRIN et al., 2016).

A propagação dessa manufatura avançada consiste no conjunto de tecnologias da informação aplicadas ao ambiente de produção, o que Schwab (2016) nomeia de "megatendências". Algumas delas são a Internet das Coisas (IOT), a Internet dos Serviços (IoS), Sistemas Ciber Físicos (CPS), impressoras 3D, inteligência artificial (IA), grandes dados (big data), veículos autônomos, robôs avançados, nanomateriais e nanosensores (SCHWAB, 2016; Confederação Nacional da Indústria, 2016; The Boston Consulting Group, 2015). 
Fortalecendo o conceito, segundo Schwab (2016), não é o conjunto de tecnologias emergentes que definem o que é a quarta revolução industrial, mas a transição em direção a novos sistemas que foram formados a partir da infraestrutura correspondente a revolução digital.

Esses novos avanços tecnológicos levaram tanto à motivação sobre a capacidade dos algoritmos de aprendizado da máquina (AM) quanto à automação para impulsionar o crescimento econômico, e também à preocupação com o destino dos trabalhadores humanos em um mundo no qual os algoritmos de computador podem executar muitas das funções humanas (FURMAN, 2016).

Neste cenário, a automação tornou-se um grande receio das pessoas empregadas nos últimos anos, tanto nos países desenvolvidos quanto nos subdesenvolvidos. Há uma preocupação extensa hoje em dia de que as tecnologias oriundas do aprendizado da máquina (AM) criem desemprego em massa durante os próximos anos (HERNANDEZ-PERDOMO, GUNEY E ROCCO, 2018).

Aqueles que possuem menor qualificação podem estar mais vulneráveis e com maior risco de não se manterem no mercado de trabalho, pois a automação tem a capacidade de substituir as tarefas exercidas por estes profissionais (Unido 2016, Indústria 4.0 oportunidades e desafios da nova revolução industrial para os países em desenvolvimento e as economias em transição). Desse modo, o estudo aborda uma temática não só respeito das vantagens oferecidas pela tecnologia. Mas, demonstrar os impactos dos avanços tecnológicos principalmente em relação a perspectiva e aos riscos enfrentados pelos trabalhadores do futuro.

Em vista disso, segundo Gorecky et al. (2014), o propósito da indústria.4.0 não é eliminar os trabalhadores para produção, mas sim complementar. É possível alcançar melhorias na produção a partir de um trabalho realizado por meio de sistemas automatizados e seres humanos.

\subsection{Impactos dos avanços tecnológicos}

Inúmeras revoluções estimuladas principalmente por novas tecnologias e por novas formas de perceber o mundo, provocaram transformações nos sistemas econômicos e nas estruturas sociais (SCHWAB, 2016).

Segundo um estudo realizado pela Organização para a Cooperação e Desenvolvimento Econômico (OCDE, 2017), a Indústria 4.0 compreende um 
conjunto de tecnologias que causam mudanças nos modelos tanto de produção quanto de consumo. Nesse sentido, percebem-se impactos relevantes na produtividade, na produtividade, na taxa de emprego, nas habilidades a serem desenvolvidas, nos mercados e no bem-estar social.

Ramaswamy (2018) considera automação quando uma máquina faz um trabalho que poderia ter sido realizado anteriormente por uma pessoa, e, hoje em dia, a maioria das tarefas manuais rotineiras, manuais não rotineiros e alguns tipos de tarefas rotineiras cognitivas e não rotineiras podem automatizar-se.

Para Coelho (2016), o impacto da Indústria 4.0 passa por uma forma muito mais complexa de inovação, pois ela se baseia na combinação de múltiplas tecnologias, que obrigaram as empresas a reverem a forma como gerem os seus negócios e processos, de como se posicionam na cadeia de valor, como pensam no desenvolvimento de novos produtos e os introduzem no mercado, ajustando as ações de marketing e de distribuição.

A inteligência artificial e os algoritmos para big data agora estão ingressando em domínios dependentes de reconhecimento de padrões. Assim, podem substituir o trabalho de tarefas cognitivas não rotineiras. Acrescentandose a isso, robôs avançados que estão sendo aperfeiçoados e estão ganhando sentidos aprimorados e destreza, que lhes permitem executar uma ampla variedade de tarefas manuais. Portanto, a natureza do trabalho pode sofrer algumas mudanças em profissões e empresas (BRYNJOLFSSON; MCAFEE, 2011).

Segundo uma pesquisa "O futuro do trabalho", divulgada no fórum Econômico de Davos (2016), essas transformações e evoluções devem provocar um corte de 7,1 milhões de postos de trabalho nos próximos cinco anos. Isso porque as indústrias inteligentes passarão por reformulação no chão de fábrica.

Entretanto, durante uma conferência da Universidade de Stanford, em seu encontro New Breakthroughs in Computational Law - Code X Future Law Conference 2015, Verheij (2015) explicou a necessidade da intervenção humana no emprego. Apesar da grande capacidade da inteligência artificial na substituição do trabalho humano em muitas áreas do conhecimento, a atuação do ser humano se faz necessária, em especial, em situações que envolvem procedimentos cognitivos e relações que tangenciam processos emocionais.

Fortalecendo este conceito, Susskind (2017, p. 117) compreende que, embora as máquinas possuam capacidades físicas (movimentos mais velozes e levantamento de cargas mais pesadas), há de se destacar o domínio do ser 
humano sobre certos tipos de tarefa, em especial aquelas relacionadas ao uso das capacidades perceptivas, emocionais e cerebrais.

Portanto, muitos empregos irão desaparecer enquanto novos irão surgir. Porém, o fator determinante será a qualificação demandada por estas novas funções. Um dos desafios em relação a indústria 4.0 é o desenvolvimento de capacidade dos trabalhadores (SYNNES; WELO, 2016; POSSELT et al., 2016). Uma sugestão para evitar o desemprego em escala é por intermédio de atualização dos trabalhadores para terem seus conhecimentos reciclados e a educação é o desafio. No entanto, a estrutura adequada e eficiente para investir na educação também é uma dificuldade. Esta realidade pode proporcionar um impacto negativo para os trabalhadores de baixa qualificação.

Para o desenvolvimento destas nova tarefas é preciso que os profissionais conheçam e desenvolvam continuamente as competências requeridas pelo mercado no século XXI que podem não ser as mesmas exigidas do século $\mathrm{XX}$. Se não houver adaptabilidade por parte destes ao atual contexto, provavelmente não se manterão competitivos para o mercado de trabalho. Como apontam Savickas et al. (2009), "os trabalhadores precários da era da informação deverão tornar-se aprendizes permanentes, capazes de utilizar tecnologias sofisticadas, assumir a flexibilidade ao invés da estabilidade, manter a sua empregabilidade e criar as suas próprias oportunidades" (p. 393).

Diante do exposto, há uma exigência maior pelas organizações por profissionais qualificados para atividades complexas. Desse modo os empregados devem estar preparados e capacitados para as novas competências relacionadas aos modelos de negócios e tecnologias embarcados na quarta revolução industrial (SCHWAB, 2017).

\subsection{Novos trabalhos e novas profissões}

O Plano de Ciência, Tecnologia e Inovação (CT\&l) para Manufatura avançada no Brasil é uma iniciativa que contribui para a melhoria da competitividade e produtividade das empresas (Brasil, 2017). No entanto, a indústria brasileira possui um conhecimento limitado a respeito das tecnologias digitais e sua incorporação à produção para avanço da Indústria 4.0 (CNI, 2016).

Segundo Schwab (2016), o trabalho também será afetado pela quarta revolução industrial. Em meio a agilidade das transformações do mercado de trabalho, determinadas carreiras profissionais e postos de trabalho são 
interrompidas enquanto outras surgem. Entre estas, as mais recentes são as carreiras e os postos de trabalho vinculados às tecnologias informacionais e os trabalhadores alocados nas novas ocupações delas derivadas (BRAVERMAN, 1987; HUWS, 2014).

Algumas mudanças já são percebidas. Os computadores atendem com mais eficiência aos pedidos de clientes, assim, a intervenção humana torna-se menos relevante em determinadas atividades de atendimento e serviços. O crescimento da capacidade dos computadores, tarefas que foram consideradas complexas estão sendo convertidas em problemas definidos tratáveis através de soluções digitais (OSBORNE; FREY, 2014).

Diante do exposto, percebe-se que as tecnologias atuais irão transformar o mundo do trabalho. Nesse sentido, haverá mudanças relevantes na organização e gestão das empresas. Conforme se adquire melhorias no processo, consequentemente, os clientes elevam suas expectativas. Logo, as organizações devem promover inovação e agilidade nos processos em razão do aumento considerável da concorrência entre as empresas (SCHWAB, 2016; TADEU, 2016).

A demanda da competitividade no atual mercado de trabalho exige investimentos cada vez mais altos em qualificação profissional. Caracterizado pela constância e flexibilidade, o mercado de trabalho procura por profissionais adaptados às mudanças recentes, como o processo de globalização (VIDIGAL; VIDIGAL, 2013). Neste segmento, é válido ressaltar a importância da formação para o trabalho na indústria 4.0 (BUISÁN; VALDÉS, 2017).

A CNI levantou um estudo em 2016 que destaca a Indústria 4.0 e suas novas formas de produção, no referente aos seus recursos humanos, exigirá que os profissionais tenham uma formação diferente da atual, deverão ser interligadas diversas formas de conhecimento, as equipes deverão ser multidisciplinares, contempladas alto nível de conhecimento técnico e com capacidade de interação de diferentes áreas de conhecimento.

Em termos de emprego, num cenário de adoção acelerada da digitalização, a perda de 750 mil empregos por conta da substituição tecnológica seria compensada com a criação de um milhão de empregos até 2030 nos setores que serão favorecidos pela transformação econômica gerada pelos investimentos e adoção da Indústria 4.0 (BMAS, 2017). Neste contexto, a IA pode melhorar a produtividade de muitas organizações, eliminando milhões de posições de médio e baixo nível, mas também criando milhões de posições de 
nível médio e alto nível (GARTNER, 2017). O gráfico 1 aponta as consequências geradas e esperadas nos postos de emprego pela utilização de tecnologias.

Gráfico 1: Impacto das tecnologias de Inteligência Artificial nos empregos do mundo até 2025 (em milhões).

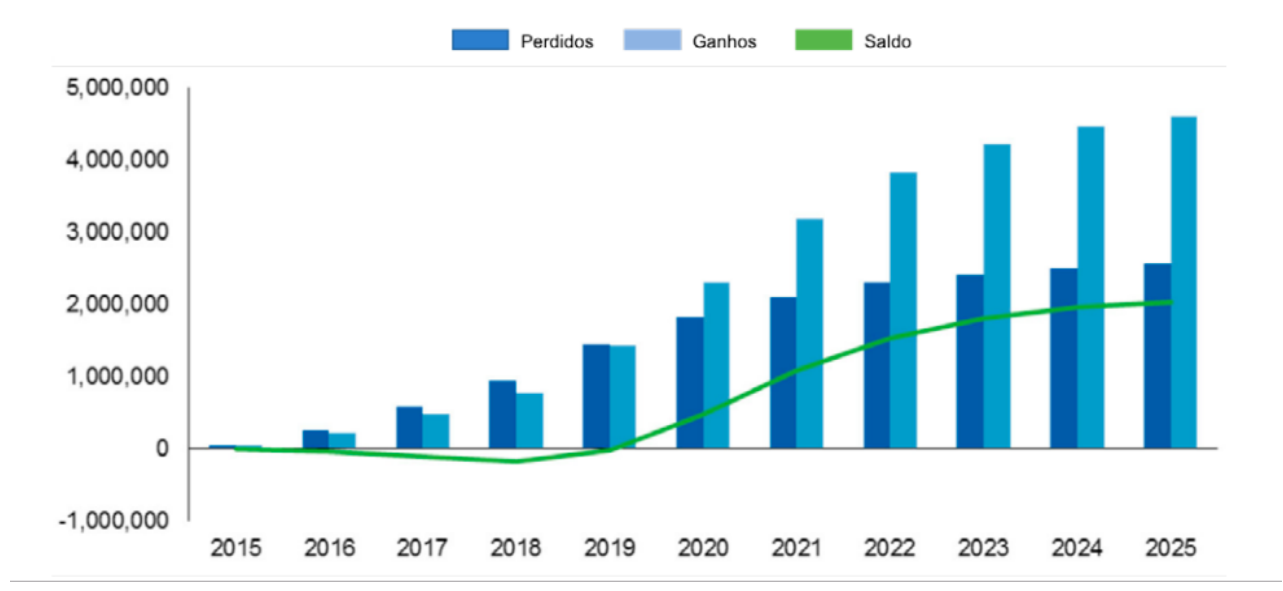

Fonte: Gartner, 2017. Adaptado pelos autores.

O impacto das tecnologias emergentes pode ser positivo para os empregos (McKinsey Global Institute, 2017). Além de 2025, novas indústrias e funções de trabalho serão criadas, mas são difíceis de prever, como, no passado, era difícil prever smartphones e redes sociais como se tem atualmente. A automação vem impulsionando a produtividade e os retornos do capital e do trabalho há 200 anos (TRUDELL; HAGIWARA; JIE, 2014).

Schwab (2016) revela que não haverá desemprego em massa, e sim a transformação e o surgimento de carreiras. Segundo o autor, haverá crescimento de emprego em cargos criativos e cognitivos de altos salários, comparando com as ocupações manuais, de baixo remuneração. $A$ tabela 1 apresenta algumas profissões mais e menos sujeitas à automação: 
Tabela 1 - Exemplo de profissões mais e menos propensas à automação

\begin{tabular}{lcc}
\hline \multicolumn{1}{c}{ Profissão } & Probabilidade & Grau de propensão \\
Operadores de telemarketing & $99,00 \%$ & alta \\
Responsáveis por cálculos fiscais & $99,00 \%$ & alta \\
Avaliadores de seguros, danos automobilísticos & $98,00 \%$ & alta \\
Árbitros, juízes e outros profissionais esportivos & $98,00 \%$ & alta \\
Secretários jurídicos & $98,00 \%$ & alta \\
Assistentes sociais de abuso de substâncias e saúde mental & $0,31 \%$ & baixa \\
Coreógrafos & $0,40 \%$ & baixa \\
Médicos e cirurgiões & $0,42 \%$ & baixa \\
Psicólogos & $0,43 \%$ & baixa \\
Gerentes de recursos humanos & $0,55 \%$ & baixa \\
\hline
\end{tabular}

Fonte: Adaptado de Schwab (2016)

O crescente papel dos grandes dados (big data) na economia e nos negócios criará a necessidade de aporte significativo de estatísticos e analistas de dados, estimado em 250.000 cientistas apenas nos Estados Unidos na próxima década. A tecnologia digital também estimulará novas formas de atividade empresarial. Empreendedores e trabalhadores em pequenas empresas e profissões autônomas podem se beneficiar de maiores oportunidades de trabalho e renda (MGI, 2017).

A visão das empresas é somar e combinar as habilidades mais fortes de humanos e robôs de forma a melhorar a eficiência da operação e mesmo libertar os indivíduos de parte de movimentos desgastantes ou repetitivos (ABB, 2018). Robôs são consistentes, confiáveis e não se cansam, mas não improvisam bem. As mudanças nas linhas de montagem exigem uma reprogramação minuciosa pelos humanos. A solução seria conciliar inteligência artificial para orquestrar os processos produtivos, programando robôs e distribuindo tarefas aos humanos que trabalham ao lado deles (MCDERMOTT, 2018).

Segundo um estudo publicado pelo Instituto de Estudos para o Desenvolvimento Industrial (2017), uma sugestão de política para a indústria 4.0 no Brasil é referente a capacitação dos recursos humanos em diversos níveis de formação, em instituições de pesquisa e nas tecnologias habilitadoras da Indústria 4.0.

Nesse sentido, metade do mundo pode estar desempregada em 2050 caso os sistemas socioeconômicos não corresponderem a globalização digitalizada, avanços da tecnologia e integração (GLENN; FLORESCU, 2015). 


\subsection{Desenvolvimento profissional na Indústria 4.0}

O objetivo do desenvolvimento profissional (DP) no campo da administração está relacionado a empregabilidade, a carreira e principalmente ao desempenho no trabalho. O desenvolvimento de competências no trabalho tem sido um conceito central para compreender as transformações que ocorrem no sistema de desenvolvimento das pessoas (Gondim, Souza, \& Peixoto, 2013).

O conceito de empregabilidade compreende um conjunto de competências relevantes para um indivíduo conquistar e manter um trabalho (CAMPOS, 2011). Diante disso, há uma maior necessidade dos trabalhadores investirem na formação profissional. Segundo Aranha (2001, p. 281), entende-se por empregabilidade a responsabilidade do trabalhador pela obtenção e manutenção do seu emprego, por meio de um processo contínuo de formação e aperfeiçoamento. Assim, os indivíduos têm maior possibilidade de deter uma posição conceituada no mercado de trabalho assegurando sua empregabilidade através do desenvolvimento das competências requeridas para o século XXI.

Segundo Fleury et al (2008), competências são conceituadas como o conjunto de conhecimento, habilidades e atitudes, assim os desempenhos organizacionais estão relacionados com a inteligência e a personalidade de cada indivíduo. Neste sentido, as competências são recursos essenciais exigidos pelas empresas, pois através destas é possível manter uma equipe de trabalho eficiente e eficaz. Diante disto, os empregados devem deter essas competências para conseguir um emprego e atuar de forma competitiva no mercado de trabalho.

De acordo com o relatório produzido pelo Conselho Nacional de Pesquisa de Washington (2012), há três amplos domínios de competências necessárias para a vida e para o trabalho no século XXI - cognitivo, intrapessoal e interpessoal. O domínio cognitivo envolve estratégias e processos de aprendizado, criatividade, memória e pensamento crítico; o domínio intrapessoal compreende a capacidade de lidar com emoções e moldar comportamentos para atingir objetivos e o domínio interpessoal está associado a expressão de ideias, interpretação e capacidade de relacionar com outras pessoas. A figura 1 exemplifica algumas competências em seus respectivos domínios. 


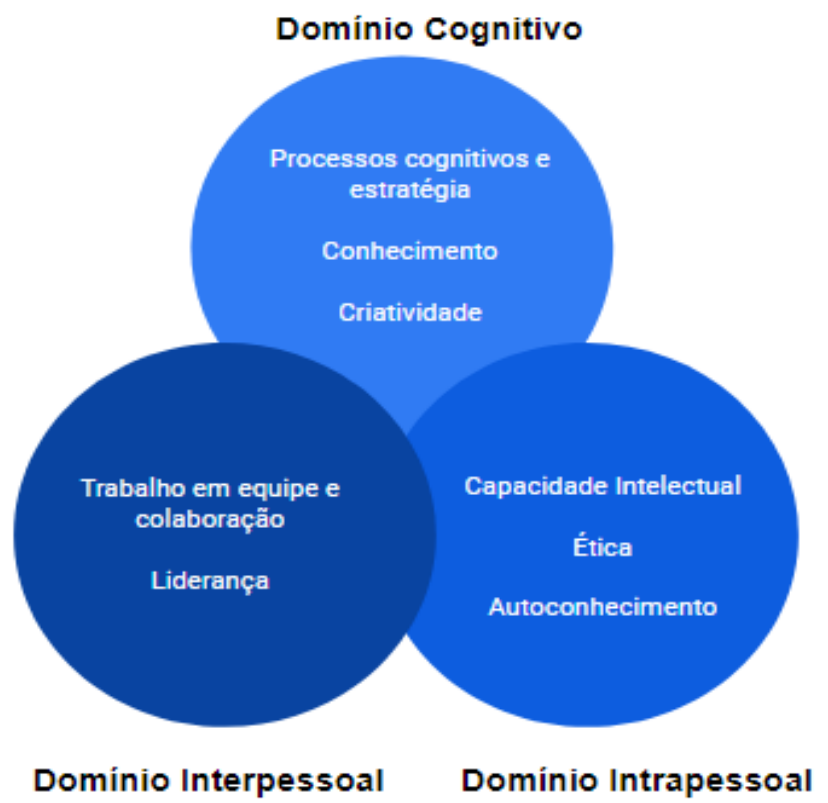

Fonte: Adaptado de Conselho Nacional de Pesquisa de Washington (2012)

O domínio cognitivo é composto pelos processos cognitivos e estratégia, conhecimento e criatividade. Os processos cognitivos e estratégia englobam pensamento, resolução de problemas, tomadas de decisão, aprendizado contínuo, análise e argumentação. O conhecimento está relacionado à informação através da tecnologia, conhecimento científico, comunicação verbal, escrita e sonora. Enquanto que a criatividade está ligada à inovação.

O domínio intrapessoal é desenvolvido através da capacidade intelectual, ética e autoconhecimento. No tocante a capacidade intelectual é preciso flexibilidade, adaptabilidade, curiosidade e aprendizado contínuo. Com relação à ética, o que prevalece são a integridade, responsabilidade, cidadania, iniciativa e profissionalismo. O autoconhecimento é o conhecimento de si mesmo, das próprias características e sentimentos, ou seja, auto avaliação a respeito da saúde física e psicológica. É compreender a personalidade e identificar o que motiva as emoções.

O domínio interpessoal é formado pelo trabalho em equipe e liderança. O trabalho em equipe e colaboração envolvem comunicação, cooperação, relacionamento interpessoal, empatia, confiança, resolução de conflitos e negociação. As características relacionadas à liderança são responsabilidade, influência, carisma e comunicação.

A seguir, na tabela 2, são exemplificadas as habilidades em suas respectivas competências exigidas para o século XXI de acordo com o Conselho Nacional de Pesquisa (2012). 
Tabela 2 - Competências exigidas para o século XXI

\begin{tabular}{|c|c|c|}
\hline Competências & Grupos & $\begin{array}{c}\text { Habilidades requeridas para o } \\
\text { século XXI }\end{array}$ \\
\hline \multirow{3}{*}{$\begin{array}{l}\text { Competências } \\
\text { Cognitivas }\end{array}$} & $\begin{array}{l}\text { Processos } \\
\text { Cognitivos e } \\
\text { estratégias }\end{array}$ & $\begin{array}{l}\text { Pensamento crítico; resolução de } \\
\text { problemas; tomada de decisão, } \\
\text { aprendizado contínuo e argumentação }\end{array}$ \\
\hline & Conhecimento & $\begin{array}{l}\text { Informação através da tecnologia; } \\
\text { conhecimento científico; comunicação } \\
\text { verbal, escrita e sonora }\end{array}$ \\
\hline & Criatividade & Inovação \\
\hline \multirow{2}{*}{$\begin{array}{l}\text { Competências } \\
\text { Interpessoais }\end{array}$} & $\begin{array}{l}\text { Trabalho em equipe } \\
\text { e colaboração }\end{array}$ & $\begin{array}{l}\text { Comunicação; cooperação; } \\
\text { relacionamento interpessoal; empatia; } \\
\text { confiança; resolução de conflito e } \\
\text { negociação }\end{array}$ \\
\hline & Liderança & $\begin{array}{l}\text { Responsabilidade; influência; carisma e } \\
\text { comunicação }\end{array}$ \\
\hline \multirow{3}{*}{$\begin{array}{l}\text { Competências } \\
\text { Intrapessoais }\end{array}$} & $\begin{array}{l}\text { Capacidade } \\
\text { intelectual }\end{array}$ & $\begin{array}{l}\text { Flexibilidade; adaptabilidade; curiosidade; } \\
\text { aprendizado contínuo e incentivo à } \\
\text { diversidade }\end{array}$ \\
\hline & Ética & $\begin{array}{l}\text { Responsabilidade; integridade; cidadania; } \\
\text { iniciativa e profissionalismo }\end{array}$ \\
\hline & Autoconhecimento & $\begin{array}{l}\text { Conhecimento de si mesmo, das próprias } \\
\text { características e sentimentos. Auto } \\
\text { avaliação a respeito da saúde física e } \\
\text { psicológica. Compreender a } \\
\text { personalidade e identificar o que motiva } \\
\text { as emoções. }\end{array}$ \\
\hline
\end{tabular}

Fonte: Adaptado de Conselho Nacional de Pesquisa de Washington (2012)

Devido às mudanças econômicas e sociais que se têm analisado a nível mundial, o desenvolvimento das competências requeridas para o século XXI é necessário para o trabalhador alcançar o sucesso individual e coletivo (ROTHERHAM \& WILLINGHAM, 2009). Porém, vale destacar que essas competências não são novas. O pensamento crítico e a resolução de problemas, 
por exemplo, são dimensões associadas ao desempenho acadêmico e aos processos de ensino e aprendizagem (VOOGT \& ROBLIN, 2012).

Diante do exposto, vale ressaltar a pesquisa realizada pela Word Economic Forum (WEF, 2015) que investigou as principais habilidades do século $\mathrm{XXI}$ requeridas pelos profissionais diante dos avanços tecnológicos. Os resultados foram voltados para as habilidades voltadas para o humano, ou seja, empatia, capacidade emocional, análise e tomada de decisões.

Diante do exposto, essa pesquisa pretende investigar a percepção dos jovens estudantes universitários do curso de administração a respeito das competências requeridas e os desafios enfrentados no mercado de trabalho em relação a indústria 4.0 no século XXI. 


\section{Metodologia}

Neste capítulo será apresentada a metodologia de pesquisa utilizada, assim como o tipo de pesquisa e suas fontes de informação. Aborda também os procedimentos e instrumentos de coleta de dados, além do tratamento desses dados e as limitações enfrentadas durante a pesquisa.

\subsection{Tipo de pesquisa}

O presente estudo foi realizado por meio de uma pesquisa descritiva no tocante às percepções dos jovens universitários em relação aos desafios enfrentados com a indústria 4.0 e seu desenvolvimento profissional compreendendo as competências requisitadas para o século XXI. De acordo com Vergara (2005), é possível classificar as pesquisas através de dois critérios: quanto aos fins e quanto aos meios.

Em relação aos fins, a natureza da pesquisa é descritiva, pois tem o objetivo de identificar as percepções dos jovens estudantes universitários frente às novas tendências do mercado. Segundo Vergara (2005), este tipo de pesquisa expõe características de determinada população ou de determinado fenômeno.

Quanto aos meios, foi realizada a pesquisa de campo mediante entrevistas como base para coleta de dados dos sujeitos estudados. Assim, foi possível levantar ideias e percepções relevantes sobre o tema. Na pesquisa de campo estudou-se um único grupo ou comunidade em termos de sua estrutura social (GIL, 2002). Complementando este conceito, para Vergara (2005) pesquisa de campo é uma investigação empírica, realizada no local da ocorrência do fenômeno ou em ambiente que disponha de elementos para explicá-lo.

\subsection{Procedimentos e instrumentos de coleta de dados}

O processo de coleta de dados se deu por entrevistas possibilitando a maximização de informações referente às percepções do público questionado. 
As entrevistas seguiram um roteiro semiestruturado composto por 11 perguntas abordando questões relevantes para a compreensão do tema de estudo. Contudo, como as respostas dos entrevistados eram livres, havia uma flexibilidade em relação ao roteiro que poderia ser adaptado durante o diálogo dependendo das respostas dos entrevistados. As entrevistas foram feitas pessoalmente, gravadas com a autorização do entrevistado e transcritas para análise.

O propósito do roteiro da entrevista foi investigar as percepções dos jovens estudantes universitários do curso de administração a respeito dos desafios gerados pela Indústria 4.0 e as competências requeridas neste atual contexto. As perguntas foram feitas para buscar informações que ajudassem a compreender as perspectivas dos jovens em relação ao mercado de trabalho.

\subsection{Formas de tratamento e análise dos dados coletados para o estudo}

Para análise dos dados, foi utilizada a técnica de análise qualitativa considerando o referencial teórico e a interpretação das respostas dadas nas entrevistas. A finalidade deste método é fazer uma observação das respostas dos entrevistados para compreender as percepções dos jovens universitários que cursam administração em relação ao seu desenvolvimento profissional e os desafios no âmbito do mercado de trabalho frente aos avanços tecnológicos.

Segundo Gil (2008), o elemento humano no trabalho do pesquisador na análise qualitativa é fundamental. Não há fórmulas ou receitas predefinidas para guiar os pesquisadores. Deste modo, a análise de dados na pesquisa qualitativa passa a depender muito do estilo e conhecimento do pesquisador.

\subsection{Limitações do método}

Determinadas limitações e dificuldades são apresentadas quanto a coleta e ao tratamento dos dados pelo método escolhido para pesquisa. A limitação da análise qualitativa pode se dar através da seleção dos atores para as entrevistas, pois não foi possível entrevistar todos os alunos formandos em Administração. Nesse sentido, é possível que os grupos selecionados para a entrevista não tenham sido os mais representativos para o tema abordado. Além disso, há a possibilidade destes fornecerem respostas que não correspondem às suas verdadeiras opiniões. 
Outra limitação deve-se a habilidade da entrevistadora, qualquer falha pode influenciar as respostas dos entrevistados. Uma outra possível limitação se dá pela percepção da pesquisadora em relação a análise das falas dos entrevistados.

Apesar das barreiras, devido a contemporaneidade do tema a pesquisa se mostra adequada com a metodologia utilizada. 


\section{Apresentação e análise dos resultados}

Para o desenvolvimento da pesquisa, julgou-se a importância da realização de entrevistas com os universitários. Portanto, o propósito deste capítulo visa apresentar e discutir os principais resultados alcançados a partir da análise feita pelas entrevistas.

Os sujeitos pesquisados foram alunos matriculados no curso de administração de uma universidade particular no Rio de Janeiro, caracterizada por ser uma instituição comunitária de educação superior. A tabela 3 ilustra as referências demográficas mais relevantes a respeito dos entrevistados com a finalidade de compreender os perfis estudados. Desse modo, as entrevistas foram realizadas por 12 universitários, sendo cinco homens e 7 mulheres com idades entre 21 e 29 anos. Maior parte dos entrevistados estavam estagiando, apenas 3 estudantes

\begin{tabular}{|c|c|c|c|c|}
\hline Entrevistado & Gênero & Idade & $\begin{array}{c}\text { Mercado de } \\
\text { trabalho }\end{array}$ & Área \\
\hline Entrevistado 1 & Feminino & 21 & Estagiária & Comercial \\
\hline Entrevistado 2 & Feminino & 22 & Estagiária & Recursos Humanos \\
\hline Entrevistado 3 & Feminino & 23 & Estagiária & Infraestrutura predial \\
\hline Entrevistado 4 & Feminino & 21 & Estagiária & Finanças \\
\hline Entrevistado 5 & Feminino & 29 & Estagiária & Recursos Humanos \\
\hline Entrevistado 6 & Masculino & 27 & Estagiário & Operações \\
\hline Entrevistado 7 & Feminino & 26 & Estudante & - \\
\hline Entrevistado 8 & Masculino & 24 & Estagiário & Compras/ Finanças \\
\hline Entrevistado 9 & Masculino & 24 & Estagiário & Operações \\
\hline Entrevistado 10 & Feminino & 21 & Estagiária & Recursos Humanos \\
\hline Entrevistado 11 & Masculino & 24 & Estagiário & Finanças \\
\hline Entrevistado 12 & Masculino & 26 & Estudante & - \\
\hline
\end{tabular}

Tabela 3: Dados demográficos dos entrevistados. Fonte: autoria própria 


\subsection{Conhecimento sobre a Indústria 4.0}

Conforme Schwab (2016), a quarta revolução industrial pode ser definida como novos sistemas que foram formados sobre a infraestrutura da revolução digital. Conforme Gorecky, a Indústria 4.0 pretende relacionar o trabalho entre sistemas automatizados e humanos com o intuito de proporcionar melhorias na produção.

A Indústria 4.0 combina diversas tecnologias inovadoras como por exemplo robótica avançada, impressão 3D, Big Data, computação em nuvem, inteligência artificial, Internet das Coisas (IOT) e materiais inteligentes. O uso destas de maneira combinada ou isolada contribuirão de forma a levar a indústria brasileira a um novo patamar de produtividade proporcionando mudanças. (SCHWAB, 2016; CNI, 2016).

A Organização para a Cooperação e Desenvolvimento Econômico (2017) apontou que os impactos causados pela indústria 4.0 estão relacionados às mudanças nos modelos de produção e consumo tanto das organizações quanto da sociedade do futuro. Através do atual contexto, percebe-se consequências relevantes no mercado, na produtividade, na taxa de emprego e nas qualificações a serem desenvolvidas.

Os entrevistados não souberam definir o que caracteriza a quarta revolução industrial. Apresentaram pouco conhecimento a respeito do assunto, segundo seus relatos, por ser um tema contemporâneo e pouco discutido na universidade. Porém, os alunos conseguem ter uma ideia objetiva e coesa a respeito das suas consequências e impactos no mercado de trabalho, que serão apresentadas a seguir.

\subsubsection{Aspectos positivos da Indústria 4.0}

No geral, os estudantes acreditam que a Indústria 4.0 proporcionará oportunidades e benefícios para as empresas, consumidores e para os colaboradores.

Essa ideia fortalece a visão de Cheng et al. (2015) que analisa o desenvolvimento na produtividade, redução dos custos de produção e melhorias na qualidade do atendimento ao cliente a partir dos avanços tecnológicos. 


\subsubsection{Impactos para o trabalho}

Um aspecto positivo sobre os impactos da indústria 4.0 que os universitários mencionaram abertamente foi em relação às mudanças no trabalho. Eles acreditam que algumas vagas de emprego serão extintas, porém outras funções irão surgir. Ou seja, as tecnologias irão substituir alguns empregos com tarefas repetitivas para funções que exigem mais raciocínio para tomar decisão. Neste sentido, a entrevistada 5 compartilhou uma experiência que ocorreu em seu trabalho. Segundo ela:

"O contador da empresa tinha muitos funcionários na parte de departamento pessoal e hoje em dia ele só tem três ou quatro em uma empresa grande. Os demais foram substituídos por um programa. É meio que substituição da mão da mão de obra. Eu acredito que seja um facilitador para as empresas, pois o custo diminui."

Essa ideia reforça o conceito de Brynjolfsson (2011) de que as tecnologias estão sendo aperfeiçoadas a ponto de executar diversas tarefas manuais. Portanto, notam-se algumas mudanças acerca da natureza do trabalho tanto para empregados quanto para empregadores. Segundo Schwab (2016), não haverá desemprego com as novas tecnologias, no entanto haverá mudanças no trabalho. Segundo o autor, ocorrerá uma queda em ocupações manuais de baixa remuneração, mas espera-se aumento significativo no nível de empregos de cargos criativos e cognitivos de altos salários.

\subsubsection{Impactos para as empresas}

Determinados entrevistados percebem que um dos benefícios para as empresas é a possibilidade de ter uma base de dados com informações relevantes a respeito dos clientes e fornecedores para tomar decisões criando vantagem competitiva. Além disso, ressaltam a possibilidade de oferecer mais inovação e informação aos clientes especializando cada vez mais um produto.

A partir da compreensão dos entrevistados, é possível correlacionar com a perspectiva de Bahrin et al. (2016) que diz sobre os efeitos eficientes de custo e melhorias na qualidade dos serviços a partir da auto-otimização, autoconfiguração e inteligência artificial das máquinas. Além disso, consolida um estudo realizado pela McKinsey Global Institute (MGI, 2017) que informa uma necessidade de aporte significativo de profissionais estatísticos e analistas de dados para trabalharem com as tecnologias como inteligência artificial e grandes dados. 
Seguindo essa mesma perspectiva, determinados entrevistados acreditam que assim há maior possibilidade das empresas alcançarem eficiência, gerarem novas ideias e terem uma visão global do mercado. A entrevistada 10 apresentou seu ponto de vista a respeito desta revolução.

"Eu acho que essa indústria tem tudo para impactar positivamente o as empresas, trabalho e o desenvolvimento das empresas. Por isso, hoje em dia temos muitas empresas unicórnios que faturam um bilhão em um ano, se não fosse a tecnologia nunca estaríamos tão avançados em questão de inovação. Eu acho que isso só vem a acrescentar em questão de inovação. O emprego de ninguém será roubado, os indivíduos terão que se adaptar e entender qual o talento necessário para ter um diferencial e não ser comparado a uma máquina. (Entrevistada 10)."

Este argumento fortalece a referência da ABB (2018) que aponta a visão das empresas sobre utilizar as capacidades mais relevantes dos humanos e robôs com o intuito de proporcionar eficiência da operação e fazer com que a parte de movimentos desgastantes ou repetitivos sejam realizados por máquinas. Por esse ângulo, vale ressaltar que de acordo com Lydon (2015), o objetivo da indústria 4.0 é proporcionar melhorias nos processos por meio de eficiência e capacidade de satisfazer as necessidades individuais dos clientes durante um período de tempo ágil.

\subsubsection{Impactos para os funcionários}

Quando questionados a respeito dos impactos causados pela quarta revolução industrial no mercado de trabalho, os estudantes responderam de forma unânime que empregos que demandam tarefas operacionais vão acabar, porém acreditam que vai aumentar o nível de trabalhos com funções que exigem mais capacitação dos funcionários. Desse modo, indivíduos com menor qualificação serão substituídos por máquinas, porém existirá mais emprego para aqueles sabem usar as tecnologias, ou seja, possuem mais preparo. De acordo com a entrevistada 2:

"Eu acho que muitos empregos operacionais tipo a parte de departamento pessoal vai morrer, em compensação eu acho que vai existir cada vez mais empregos que exigem a parte analítica. Uma vez que vamos receber muitos dados que devem ser traduzidos para elaborar estratégias. "

Essa ideia está alinhada ao estudo da Gartner (2017), a pesquisa sugere que se por um lado os avanços tecnológicos irão eliminar 1,8 milhões de 
empregos de nível médio e baixo, por outro vai criar 2,3 milhões de novas atividades com posições que exigirão habilidades altamente qualificadas.

Os entrevistados apresentam uma perspectiva a respeito da mão de obra humana. Segundo eles, apesar dos avanços tecnológicos e dos seus benefícios, nota-se que o fator humano possui características essenciais que não podem ser substituídas pelas máquinas. Os dados fornecidos pelas tecnologias devem ser analisados pelos humanos para tomada de decisão. Em suma, a maioria dos entrevistados acredita que a indústria 4.0 vai ser essencial para dar suporte aos humanos prevalecendo o fator humano. De acordo com a entrevistada 10, os impactos causados no mercado de trabalho serão:

"Em questão de emprego eu acho que pode diminuir a demanda dos empregos que tem hoje em dia, de empregos básicos que serão substituídos por máquinas. Agora, a parte analítica que não vai ser substituída, são essas pessoas que vão se manter. "

O conceito de Verheij (2015) é fortificado pela opinião dos universitários a respeito da intervenção humana no emprego. Segundo o autor, ainda que a inteligência artificial possua atributos relevantes para substituição do trabalho humano em muitos meios, julga-se necessária a atuação do ser humano em determinadas situações como processos emocionais e procedimentos cognitivos por exemplo.

Em conformidade ao tema, segundo McDermott (2018), a inteligência artificial proporciona melhorias no processo e tarefas para os humanos. Sendo assim, é possível que trabalhem lado a lado, pois se complementam.

Portanto, percebe-se que os estudantes possuem uma concepção muito otimista sobre a indústria 4.0. Enquanto que há também desafios a serem enfrentados no âmbito social, econômico e ambiental que poucos parecem perceber.

\subsubsection{Aspectos negativos da indústria 4.0}

Tais respostas dos entrevistados reforçam a ideia de que a indústria 4.0 proporciona vantagens significativas para as organizações principalmente. No entanto, a quarta revolução industrial apresenta aspectos negativos que alguns entrevistados levantaram.

No geral, os entrevistados destacaram como desafio a qualificação exigida pelo mercado a partir do atual contexto. Os universitários percebem a importância da qualificação para não serem substituídos pelas tecnologias. 
Diante do exposto, a ideia dos alunos vai de encontro ao comentário de Hernandez-Perdomo, Guney e Rocco (2018) sobre a preocupação dos indivíduos em relação ao desemprego em massa devido aos avanços das tecnologias provenientes do aprendizado da máquina. Desse modo, segundo Savickas et al. (2009), os trabalhadores deste atual cenário devem aprender constantemente para deter qualificações. Assim, será possível atuar com as tecnologias sofisticadas e manter sua empregabilidade.

\subsubsection{Competitividade no mercado de trabalho}

Como mencionado, os universitários entendem que acontecerá uma ampliação de novos empregos com os avanços tecnológicos. No entanto, com a instabilidade econômica que o Brasil enfrenta principalmente em relação à taxa de desemprego, observa-se um aumento no nível de competitividade tornando as empresas mais rigorosas com a força de trabalho.

Reforçando a ideia de competitividade, os alunos analisam que a área de Administração é um curso que oferece diversas oportunidades, porém é muito concorrida. Além de formar muitos profissionais, os administradores concorrem à mesma vaga de emprego com pessoas de outras áreas como engenharia, economia e psicologia.

Portanto, os entrevistados analisam a concorrência no mercado de trabalho de forma predominante. Além disso, ressaltam as mudanças nos requisitos exigidos pelas empresas, hoje elas procuram pessoas mais qualificadas, com cursos de pós-graduação e de idiomas (pelo menos dois), que antes não eram exigidos. Segundo os entrevistados, isso dificulta a entrada no mercado, pois o profissional deve ter qualificação para se destacar e assim conseguir uma vaga de emprego.

Essa visão a respeito do mercado de trabalho fortalece o conceito de Vidigal (2013), que afirma que há uma ampla competitividade no mercado, por isso, as empresas estão exigindo profissionais adaptáveis e flexíveis. As pessoas devem se aperfeiçoar para lidar com as novas tecnologias e assegurar sua empregabilidade (SCHWAB, 2016)

Diante do exposto, os estudantes compreendem que há maior exigência por parte das organizações, pois as empresas solicitam pessoas mais especializadas e capacitadas. Deste modo, os indivíduos devem investir na sua capacitação para ter um diferencial. Por meio desta perspectiva, a entrevistada 1 apresentou seu ponto de vista a respeito do tema: 
"As empresas estão pedindo mais, por isso, devemos ter mais conhecimentos gerais. É necessário todo tipo de conhecimento, não necessariamente da sua área de atuação. "

A percepção dos alunos fortalece o conceito levantado por Schwab e Tadeu (2016) que as novas tecnologias vão mudar o mundo dos negócios. Portanto, as empresas devem se adaptar ao atual cenário a partir de velocidade nos processos e inovação uma vez que aumenta o nível de competitividade entre as organizações. Com a eficiência proveniente dos avanços tecnológicos, percebe-se menor necessidade da intervenção humana para algumas tarefas. Com a expansão da tecnologia, soluções digitais são usadas para determinadas funções (Osborne; Frey, 2014). Desta forma, é relevante destacar a importância da formação para o trabalho no contexto da Indústria 4.0 (BUISÁN VALDÉS, 2017).

\subsubsection{Mudanças no desenvolvimento do profissional}

Em contrapartida, os alunos levantaram a ideia de que com esses avanços, eles serão mais cobrados, pois o trabalho vai exigir capacidade de análise que são tarefas mais complexas em comparação às atividades mais operacionais. Assim, o entrevistado 11 afirmou:

"Quem tiver um passo à frente pode se dar muito bem e quem não estiver, obviamente vai acabar ficando para trás."

Os argumentos dos entrevistados tonificam o pensamento de Unido (2016) sobre possíveis ameaças dos empregados com menor qualificação. Estes indivíduos podem estar sujeitos a não se manterem no mercado de trabalho, pois possuem mais chances de serem substituídos por tecnologias. O desenvolvimento de capacidade dos trabalhadores são um dos principais desafios da indústria 4.0 (SYNNES; WELO, 2016; POSSELT et al., 2016).

Além dos pontos negativos mencionados, conforme relatos dos entrevistados, os desafios a respeito do atual cenário são as exigências no tocante ao desenvolvimento dos profissionais. Segundo os universitários, para manterem-se competitivos os trabalhadores devem ter qualificações para responder às exigências do mercado de trabalho.

Essa concepção dos entrevistados reforça o estudo da CNI (2016) em relação às exigências para os profissionais. Segundo o relatório, devido à Indústria 4.0 e consequente mudanças no processo produtivo, é 
estabelecida uma formação dos profissionais diferente da atual, além de alto nível de conhecimento técnico e multidisciplinaridade.

Dessa maneira, compreende-se que as empresas passam a exigir mais para possuir uma força de trabalho eficiente. Então os profissionais que não estiverem acompanhando os pré-requisitos exigidos pelo mercado podem não conseguir se manter competitivos para conseguir um emprego. Por isso, devem se manter atualizados, devem ter a capacidade de se reinventar e mostrarem-se mais necessários que uma máquina.

Essa compreensão dos universitários complementa o que Coelho (2016) fala sobre a complexidade de inovação da indústria 4.0, que forçou as empresas a reverem a maneira como devem gerir seus negócios e processos como um todo.

Quando questionados a respeito dos desafios, de forma geral, os universitários mencionaram as limitações do país em que vivem. De acordo com alguns alunos, muitas pessoas ainda não têm acesso à tecnologia e à educação, isso pode ser um fator dificultador para determinados indivíduos conseguirem um emprego e aceitar que o mundo está mudando. Sendo assim, eles reforçam a ideia de que o país deve investir em educação e principalmente os trabalhadores, pois o foco da quarta revolução industrial tem como proposta a educação.

A ideia dos alunos corresponde a uma publicação do Instituto de Estudos para o Desenvolvimento Industrial (2017) que sugeriu propostas de política para a Indústria 4.0 no Brasil. Uma delas é o investimento na capacitação de recursos humanos em diferentes níveis de formação nas tecnologias habilitadoras da Indústria 4.0, em instituições de pesquisa e de transferência de tecnologias para as empresas. De acordo com uma pesquisa realizada pela CNI (2016), a indústria brasileira possui pouco conhecimento sobre as tecnologias digitais e sua incorporação à produção. Os altos custos de implantação e a baixa qualificação da mão de obra são outros fatores limitantes.

Os entrevistados destacaram o custo adicional gerado pelos funcionários para deter um curso de extensão ou especialização. Visto que algumas empresas não estão dispostas a arcar com esse gasto, porém nem todos possuem disponibilidade financeira para tal. Então, segundo os alunos, o desafio é desenvolver esse conhecimento para os empregados terem acesso a informação e possuírem as qualificações necessárias para trabalhar com os recursos exigidos no atual contexto de indústria 4.0 
No entanto, de acordo com Aranha (2001), a empregabilidade é compromisso do trabalhador através de um processo constante de formação e aperfeiçoamento pela obtenção e manutenção do seu emprego.

Segundo Glenn e Florescu (2015), há a possibilidade de metade de o mundo estar desempregado caso os sistemas socioeconômicos não se adequarem aos avanços tecnológicos, integração e globalização digitalizada.

Desse modo, é válido ressaltar uma reflexão crítica em relação ao ponto de vista do empregado. Há muitas divulgações que enfatizam mais os ganhos proporcionados pela Indústria 4.0 para as organizações como aumento na produtividade, redução de custos e soluções eficazes para atender clientes. Contudo, pouco se é discutido sobre os desafios gerados para os trabalhadores de baixa qualificação. Haverá transformações no trabalho, porém os estudos não abordam quais seriam os postos de trabalhos criados e como este grupo de empregados que vão perder suas ocupações serão incorporados nos novos trabalhos que surgirão. Acredita-se que eles deveriam ter uma base de ensino por parte do país onde está inserido, porém esta não é a realidade da maioria.

Nesse sentido, os avanços tecnológicos decorrentes da Indústria 4.0 deveriam servir todos os agentes envolvidos como empresas, colaboradores e consumidores. Portanto, o estudo reforça a necessidade de investigar e refletir melhor sobre os impactos causados pela quarta revolução industrial sob a visão do trabalhador no ambiente de trabalho.

\subsection{Competências para o século XXI}

De acordo com Gondim, Souza e Peixoto (2013), a evolução profissional das pessoas está atrelada ao desenvolvimento de competências no trabalho. Através desta perspectiva e das mudanças no mercado de trabalho, buscou-se compreender a percepção dos universitários a respeito das competências requeridas para o século XXI. Quando perguntados a respeito das competências solicitadas pelo ambiente de trabalho, os entrevistados apresentaram opiniões semelhantes.

Segundo os alunos, o trabalhador deve ser capaz de absorver as novidades e as tendências do mercado devido às mudanças na natureza do trabalho e o fluxo constante de informações. Desse modo, é necessário ter um bom desenvolvimento do negócio, analisar o mercado e entender de tecnologia.

Nessa perspectiva, segundo os relatos de alguns universitários, os empregados devem ter adaptabilidade e flexibilidade para trabalhar em um 
mercado complexo e dinâmico. Isso implica na capacidade de aprendizado do colaborador que deve aprender rapidamente para entender e responder às mudanças contínuas que ocorrem.

Essas competências mencionadas pelos alunos corroboram com 0 conceito apresentado pelo Conselho Nacional de Pesquisa de Washington (2012). Esse conjunto de habilidades e atitudes estão inseridas no domínio intrapessoal que é a capacidade do indivíduo em identificar seus sentimentos e emoções para saber lidar com as situações.

Conforme determinados entrevistados, ainda que existam os avanços tecnológicos, as organizações são compostas por pessoas. Nesse sentido o trabalho em equipe, comunicação e relacionamento interpessoal são fatores chave para as empresas apresentarem resultados. Por isso, espera-se que tais competências sejam solicitadas pelo mercado. O entrevistado 9 exemplificou uma situação que ocorreu entre ele a empresa em que hoje trabalha:

\footnotetext{
"Basicamente eu consegui ser efetivo porque a minha superior percebeu que eu tinha capacidade de trabalho intrínsecas, além das capacidades técnicas que ela havia percebido quando me contratou para ser estagiário. Ela observou que eu era bom em comunicação, relacionamento interpessoal e bom em solucionar problemas. Eu acredito que esses são os atributos que as pessoas devem ter daqui para frente para não serem substituídas por outras coisas da indústria."
}

Permanecendo com o estudo realizado pelo Conselho Nacional de Pesquisa de Washington (2012). As competências destacadas pelos alunos reforçam o princípio de competências interpessoais que é caracterizado pela capacidade de entender as pessoas como uma das principais competências exigidas no mercado de trabalho para o século XXI.

As competências cognitivas desenvolvidas pelo Conselho Nacional de Pesquisa de Washington (2012) também foram discutidas pelos universitários. De acordo com eles, a capacidade de aprendizado contínuo, saber lidar com conflitos, conhecimento e criatividade são características fundamentais para todos os profissionais da área.

No geral, os alunos entendem que as competências intrapessoais, interpessoais e cognitivas são domínios necessários. Segundo os universitários, especializações não serão suficientes para os trabalhadores do futuro se manterem no mercado de trabalho. Reforçam que para ter um diferencial, é preciso deter as competências. Paralelo a isso, segundo a entrevistada 2:

"Vejo hoje em dia um movimento do mercado em busca de pessoas com competências como capacidade de aprendizado, comunicação, 
autoconhecimento e visão global. Acredito que pessoas com essas competências serão diferenciadas e mais desejadas pelo mercado."

\subsubsection{Competências no presente e no futuro no mundo do trabalho}

De modo geral, quando se fala sobre o futuro, os entrevistados reforçaram as competências que hoje são vistas como essenciais para o século XXI.

De acordo com os alunos, em virtude dos avanços na tecnologia, o mercado estará sempre mudando e a inovação mostra-se fundamental nos próximos anos. Para os universitários essas mudanças têm ocorrido desde a primeira revolução industrial, então eles entendem que as transformações não sejam diferentes daquilo que já presenciaram. Nesse sentido, percebem-se novas maneiras no processo produtivo. Porém, as competências exigidas serão as mesmas que se têm hoje.

Conforme relatos dos entrevistados, as máquinas não vão substituir as pessoas, pois o ser humano tem capacidade de construir relações e analisar. Desse modo, as competências eram e continuam sendo voltadas para a capacidade de olhar para si mesmo, analisar fatores externos e de aprendizado. Desenvolver inteligência emocional e construir empatia são habilidades que não podem ser substituídas pelas máquinas.

Essa percepção reforça o que Susskind (2017) fala a respeito do domínio do ser humano sobre determinadas tarefas. Mesmo com as vantagens disponibilizadas pelas máquinas, é preciso reconhecer a necessidade da intervenção humana para algumas tarefas que envolvem a capacidade emocional, perceptiva e cerebral.

Mediante aos avanços tecnológicos, as habilidades fundamentais para os profissionais são voltadas para o humano, isto é, capacidade intrínseca de reflexão, empatia, emoção, análise e tomada de decisões do ser humano (WEF, 2015).

Competências como liderança, adaptabilidade, capacidade de aprendizado comunicação, trabalho em equipe, relacionamento interpessoal e criatividade foram mencionadas pela maioria dos entrevistados ao serem questionados sobre as competências requeridas nos próximos 10 anos. 
Diante do exposto, surge uma reflexão em relação à dimensão das competências no mercado de trabalho. Ao pesquisar sobre o tema, muitos estudos ressaltam a importância do desenvolvimento das competências nas instituições de ensino e nas empresas. No entanto, vale ressaltar a profundidade e relevância que envolvem o assunto.

Com base nas entrevistas, foi possível analisar que as competências requeridas atualmente possuem uma imagem fundamental, porém os alunos julgam que daqui a 10 anos as mesmas serão exigidas ainda que ocorram transformações no mercado devido aos avanços tecnológicos e inovações. Desse modo, levanta-se uma observação se de fato as competências representam uma mudança expressiva ou se ganham valor devido a uma linguagem comercial.

É possível discutir se há inovação na visão das competências atuais, uma vez que já são conhecidas como necessárias desde um tempo atrás. Por isso, o estudo sugere que as competências do século XXI são essenciais, no entanto, é importante lembrar que já eram importantes em contextos anteriores e analisar se são de fato novas competências a serem desenvolvidas ou se são as mesmas já conhecidas, repaginadas com novos rótulos sem de fato representarem mudanças para as necessidades das pessoas. 


\section{Conclusões e recomendações para novos estudos}

O incentivo deste estudo se deu pelo interesse em analisar a opinião dos estudantes de graduação sobre as mudanças no mercado de trabalho. Essas transformações são principalmente causadas pela quarta revolução industrial também nomeada de indústria 4.0 .

O assunto do estudo é contemporâneo e pouco discutido, no entanto, de suma importância para compreensão e desenvolvimento dos universitários. Portanto, compreendeu-se uma utilidade em estudar o tema sob um olhar acadêmico e compreender impactos gerados na sociedade.

Nessa perspectiva, o trabalho teve por finalidade investigar a percepção dos jovens universitários sobre as consequências da indústria $4.0 \mathrm{e}$ as competências requeridas no século XXI a partir deste atual contexto. Sendo assim, para elaboração do presente relatório buscou-se fundamentar em pesquisa bibliográfica e de campo.

O referencial teórico foi substancial para acompanhar o objetivo do trabalho. Por meio deste, foi possível explorar citações relevantes a respeito dos impactos causados pela quarta revolução industrial, as competências demandadas e a importância sobre o desenvolvimento profissional dos colaboradores para permanecerem competitivos no mercado de trabalho.

Com o intuito de deter eficiência no estudo e melhor analisar o tema, foi desenvolvido uma pesquisa qualitativa composta por um questionário para a coleta de dados. O público desta pesquisa foram formandos de graduação do curso de administração matriculados em uma instituição particular de ensino. A partir das respostas dos entrevistados, foi possível perceber que é um tema pouco abordado nas universidades, porém de extrema importância para conhecimento e para o desenvolvimento profissional.

Através da união do referencial teórico e pesquisa de campo, o estudo investigou os aspectos positivos da indústria 4.0 para o mercado de trabalho, as empresas e os colaboradores. No entanto, há impactos negativos acerca da 
visão do trabalhador que pouco se é mencionado em comparação aos efeitos positivos.

Também foram destacadas as principais competências para o século XXI mediante ao contexto da quarta revolução industrial. De acordo com o relatório produzido pelo Conselho Nacional de Pesquisa de Washington (2012), há três amplos domínios de competência - cognitivo, intrapessoal e interpessoal.

Desse modo, o estudo propõe a implementação de métodos eficazes adotando estratégias inovadoras como base para compreensão e formação dos universitários no atual mercado para Indústria 4.0. Metodologias podem ser repensadas para preparação dos alunos frente ao novo cenário que impacta diretamente a vida profissional e pessoal dos alunos.

Além disso, o trabalho sugere novas pesquisas para explorar como os indivíduos que não têm acesso à tecnologia, educação e recursos financeiros vão se manter no mercado de trabalho uma vez que profissões com tarefas operacionais serão extintas. 


\section{Referências Bibliográficas}

ABB. Yumi. (2018), Creating an Automated Future Togheter. Online. Disponível em:<<http://new.abb.com/products/robotics/industrial-robots/yumi> . Acesso em: 23 de setembro de 2019.

AFP. Produtos de inteligência artificial registram aumento de patentes. Exame Abril, 1 fev. 2019. Disponível em: <https://exame.abril.com.br/ciencia/produtos-de-inteligenciaartificial-registram-aumento-de-patentes/> Acesso em 15 de set. 2019.

Aranha, A. V. S. (2001). Formação profissional nas empresas: locus privilegiado da educação do trabalhador? In S. M. Pimenta \& M. L. Côrrea (Orgs.), Gestão, trabalho e cidadania (pp. 281-294). Belo Horizonte: Autêntica

BAHRIN, M.; OTHMAN, F.; AZLI, N.; TALIB, M. Industry 4.0: A review on industrial automation and robotic. Journal Teknologi, [s.I.], v. 78, n.6-13, p.137-143, 2016.

BMAS. Weis Buch - Arbeiten 4.0. Berlin: Bundesministerium für Arbeit und Soziales Abteilung Grundsatzfragen des Sozialstaats, der Arbeitswelt und der Sozialen, 2017: Marktwirtschaft. Online. Disponível em: $<$ https://www.bmas.de/SharedDocs/Downloads/DE/PDF-Publikationen/a883weissbuch.pdf?_blob=publicationFile> . Acesso em: 8 de novembro de 2019.

Brasil. Ministério da Ciência, T. I. E. C. Plano de CT\&I para Manufatura Avançada no Brasil. Brasília, DF, 2017: MCTIC.

BRAVERMAN, Harry. Trabalho e capital monopolista: a degradação do trabalho no século XX. Rio de Janeiro: Guanabara, 1987.

BRYNJOLFSSON, Erick; MCAFEE, Andrew. (2011), Race Against the Machine: How the Digital Revolution is Accelerating Innovation, Driving Productivity, and Irreversibly Transforming Employment and the Economy. Lexington, Massachusetts: Digital Frontier Press. Disponível em: <file:///C:/Users/sabri/Downloads/433-317-1-SM.pdf>

BUISÁN, Mario; VALDÉS, Fernando. La Industria Conectada 4.0. Revista de Economia 
Ice: La Economía Digital en España, [s.I], v. 1, n. 898, p.89-100, out. 2017. Disponível na internet $\quad<\quad$ https://circulodeempresarios.org/transformacion-digital/wpcontent/uploads/PublicacionesInteres/01.ICE\%20898.pdf>: . Acesso em: 8 de novembro 2019.

Campos, K. C. L. (2011). Construção de uma escala de empregabilidade: definições e variáveis psicológicas. Estudos de Psicologia, 28(1), 45-55. doi: 10.1590/S0103166X2011000100005

CHENG C.; GUELFIRAT, T.; MESSINGER, C.; SCHMITT, J.; SCHNELTE, M.; WEBER, $P$. Semantic degrees for industrie 4.0 engineering: deciding on the degree of semantic formalization to select appropriate technologies. In: EUROPEAN SOFTWARE ENGINEERING CONFERENCE AND THE ACM SIGSOFT SYMPOSIUM ON THE FOUNDATIONS OF SOFTWARE ENGINEERING, 10., 2015, Bergamo. Proceedings... Nova York: ACM New York, 2015. p.1010-1013.

COELHO, P. M. N.: Rumo à indústria 4.0. Dissertação (Mestrado em Engenharia e Gestão Industrial) - Faculdade de Ciências e Tecnologias, Departamento de Engenharia Mecânica. Universidade de Coimbra. Coimbra, Portugal, 2016. Disponível em: <https://estudogeral.sib.uc.pt//handle/10316/36992> Consultado em 7 de novembro de 2019.

CONFEDERAÇÃO NACIONAL DA INDÚSTRIA. Desafios para a Indústria 4.0 no Brasil. Brasília, 2016. Disponível em: < http://www.portaldaindustria.com.br/publicacoes/2016/8/desafios-para-industria-40-nobrasil/\#> Acesso em 20 de outubro de 2019.

CONSELHO NACIONAL DE PESQUISA. Educação para a vida e o trabalho: Desenvolvimento de conhecimento e habilidades transferíveis no século XXI. Washington, 2012. Disponível em: <https://www.nap.edu/catalog/13398/education-forlife-and-work-developing-transferable-knowledge-and-skills> Acesso em 25 de setembro de 2019.

CREWS, C. What machine learning can learn from foresight: a human-centered approach. Research-Technology Management, v. 62, n. 1, p. 30-33, 2019. 
Da Redação. $85 \%$ dos jovens brasileiros querem trabalhar com desenvolvimento de tecnologias. Computerworld, 12 nov. 2018. Disponível em: $<$ https://computerworld.com.br/2018/11/12/85-dos-jovens-brasileiros-querem-trabalharcom-desenvolvimento-de-tecnologias/> Acesso em: 16 set. 2019.

DOMBROWSKI, U., Wagner, T. Mental strain as field of action in the 4 th industrial revolution. In: Variety Management in Manufacturing. Proceedings of the 47th CIRP Conference on Manufacturing Systems. Procedia CIRP 17, 100-105. 2014. Acesso em 18 de outubro de 2019.

DRATH, R.; HORCH, A. Industrie 4.0: Hit or hype? IEEE industrial electronics magazine, v. 8, n. 2, p. 56-58, 2014.

FLEURY, M. T. L; et al. Competências, conceitos, métodos e experiências. São Paulo: Atlas, 2008.

FURMAN, J. Is this time different? The opportunities and challenges of artificial intelligence. Washington: NASEM, 2016. Disponível na internet: $<\underline{\text { https://www.americanai.com/is-this-time-different-the-opportunities-and-challenges-of- }}$ artificial-intelligence/> Acesso em 7 de novembro de 2019

GARTNER. Predicts 2018: Al and the future of work. [Relatório]. Stamford, 2017: Gartner. Online. Disponível em:<<http://www.commerce-associe.fr/wpcontent/uploads/predicts_2018_ai_and_the_fut_342326.pdf $>$. Acesso em: 8 de novembro de 2019.

GIL, A. C. Métodos e técnicas de pesquisa social. 6. ed. São Paulo: Atlas, 2008

GIL, A. C. Como elaborar projetos de pesquisa. 4. ed. São Paulo: Atlas, 2002

GLENN, Jerome; FLORESCU, Elisabeth. O Estado do Futuro - Sumário Executivo [Relatório]. Washington, 2015: The Millennium Project. Disponível em: <http://107.22.164.43/millennium/2015-SOF-ExecutiveSummary-Portuguese.pdf>. Acesso em: 20 de setembro de 2019.

Gondim, S. M. G., Souza, J. J., \& Peixoto, A. L. A. (2013). Gestão de pessoas. In L. O. Borges \& L. Mourão. (Orgs.), As pessoas, o trabalho e as organizações: intervenções a partir da Psicologia (pp. 343-374). Porto Alegre: Artmed. 
Gordon, J., Halsz, G., Krawczyk, M., Leney, T., Michel, A., Pepper, D., Putkiewicz, E., \& Wisniewski, W. (2009). Key competences in Europe. Opening doors for lifelong learners across the school curriculum and teacher education. Warsaw: Center for Social and Economic Research on behalf of CASE Network.

Gorecky, D., Schmitt, M., Loskyll, M., \& Zühlke, D. (2014). Human-machineinteraction in the industry 4.0 era. Proceedings - 2014 12th IEEE International Conference on Industrial Informatics, INDIN 2014, 289-294. Disponível na internet <https://doi.org/10.1109/INDIN.2014.6945523> Acesso em 7 de outubro de 2019.

HERNANDEZ-PERDOMO, E.; GUNEY, Y.; ROCCO, C. M. A reliability model for assessing corporate governance using machine learning techniques. Reliability Engineering and System Safety, n. 185, p. 220-231, 2018.

HUWS, Ursula E. Vida, trabalho e valor no século XXI: desfazendo o nó. Caderno CRH , v. 27, n. 70, p. 13-30, 2014

INSTITUTO DE ESTUDOS PARA O DESENVOLVIMENTO INDUSTRIAL. Políticas para o desenvolvimento da indústria no Brasil. São Paulo, 2018. Disponível em: $<$ https://web.bndes.gov.br/bib/jspui/bitstream/1408/15486/1/POL\%C3\%8DTICAS\%20PA RA\%200\%20DESENVOLVIMENTO\%20DA\%20IND\%C3\%9ASTRIA\%204.0\%20NO\%20 BRASIL 2018.pdf> Acesso em 23 de setembro de 2019.

LYDON, Bill. Industry 4.0: Should you bet on it? 2015. Disponível na internet: $<$ https://www.automation.com/automation-news/article/industry-40-should-you-bet-on-it.> Acesso em: 19 de outubro de 2019.

KAGERMANN, H.; WAHLSTER, W.; HELBIG, J. Securing the future of German manufacturing industry: Recommendations for implementing the strategic initiative Industrie 4.0. Frankfurt, 2013. Disponível na internet: $<$ https://www.din.de/blob/76902/e8cac883f42bf28536e7e8165993f1fd/recommendationsfor-implementing-industry-4-0-data.pdf> Acesso em 19 de outubro de 2019.

MCDERMOTT, Bill. (2018), Machines can't dream. Davos-Klosters, 2018: World Economic Forum. Online. Disponível em: 
$<$ https://www.weforum.org/agenda/2018/01/machines-can't-dream/> . Acesso em: 23 de setembro de 2019.

MGI - McKinsey Global Institute. Technology, Jobs, and the future of work. San Francisco, 2017: McKinsey Global Institute. Online. Disponível em: $<$ https://www.mckinsey.com/ /media/mckinsey/featured\%20insights/Future\%20of\%20Org anizations/What\%20the\%20future\%20of\%20work\%20will\%20mean\%20for\%20jobs\%20s kills\%20and\%20wages/MGl-Jobs-Lost-Jobs-Gained-Report-December-6-2017.ash> . Acesso em: 20 de setembro de 2019.

Nações Unidas. Com evolução tecnológica, $65 \%$ das crianças terão empregos que ainda não existem, diz CEPAL, 18 jul. 2018. Disponível na internet: $<$ https://nacoesunidas.org/com-evolucao-tecnologica-65-das-criancas-terao-empregosque-ainda-nao-existem-diz-cepal/> Acesso em 16 set. 2019.

OCDE. The Next Production Revolution: Implications for Governments and Business. OCED Publishing. Paris, p. 1-442. 2017a. (978-92-64-27103-6).

OSBORNE, Michael; FREY, Carl Benedikt. London Agiletown: the relentless march of technology and London's response. London, 2014: Deloitte. Online. Disponível na internet <https://www2.deloitte.com/content/dam/Deloitte/uk/Documents/ukfutures/london-futures-agiletown.pdf> . Acesso em: 8 de novembro. 2019.

RAMASWAMY, K. V. Technological change, automation and employment: a short review of theory and evidence. Mumbai: Indira Gandhi Institute of Development Research, 2018. (Working Paper, n. 2018-02).

Redação. Até 2020, IA criará mais empregados do que eliminará, diz Gartner. Itforum365, 28 dez. 2017. Disponível em: < https://www.itforum365.com.br/2020-ia-maisempregos-gartner/> Acesso em : 16 set. 2019.

Rosa, Bruno. Amazon ultrapassa Google e Apple e se torna a marca mais valiosa do mundo. O Globo, 11 jun. 2019. Disponível em: $<$ https://oglobo.globo.com/economia/amazon-ultrapassa-google-apple-se-torna-marcamais-valiosa-do-mundo-23732173> Acesso em 14 de set. 2019.

Rotherham, A., \& Willingham, D. (2009). 21st century skills: The challenges ahead. Educational Leadership, 67(1), 16-21. 
Vianen, A. E. M. (2009). Life designing: A paradigm for career construction in the 21st Century. Journal of Vocational Behavior, 75(3),239-250. doi:10.1016/j.jvb.2009.04.004

SCHWAB, Klaus. The Fourth Industrial Revolution. Genebra. Disponível na internet:<https://www.startse.com/noticia/nova-economia/60414/industria-4-0-entenda-oque-e-quarta-revolucao-industrial> Acesso em 6 de novembro de 2019.

SCHWAB, Klaus. A Quarta revolução industrial. São Paulo: EDIPRO, 2016.

Schwab, Klaus. The Fourth Industrial Revolution: what it means, how to respond, 2017. Disponível na internet <https://www.weforum.org/agenda/2016/01/the-fourthindustrial-revolution-what-it-means-and-how-to-respond/> Acesso em 7 de novembro de 2019.

SUSSKIND, Richard; SUSSKIND, Daniel. The future of professions: how technology will transform the work of human experts. New York: Oxford, 2017.

SYNNES, E. L.; WELO, T. Enhancing Integrative Capabilities through Lean Product and Process Development. Procedia CIRP, v. 54, p. 221-226, 2016.

TADEU, Hugo Ferreira Braga. Impactos da Indústria 4.0. Fundação Dom Cabral, Nova Lima, p.1-6, março $2016 . \quad$ Disponível em: $<$ https://www.fdc.org.br/professoresepesquisa/nucleos/Documents/inovacao/digitalizacao /boletim_digitalizacao_marco2016.pdf>. Acesso em: 15 de outubro de 2019.

TRUDELL, Craig; HAGIWARA, Yuki; JIE, Ma. Humans Replacing Robots Herald Toyota's Vision of Future.Bloomberg, New York, 7 apr. 2014, online. Disponível em:<https://www.bloomberg.com/news/articles/2014-04-06/humans-replacing-robotsherald-toyota-s-vision-of-future> . Acesso em: 20 de setembro de 2019.

UNIDO. Indústria 4.0 oportunidades e desafios da nova revolução industrial para os países em desenvolvimento e as economias em transição, 2016. Disponível na internet $\quad<$ https://www.unido.org/sites/default/files/2017-01/Unido industry4 NEW 0.pdf $>$ Acesso em 7 de novembro de 2019

Vergara, S. C. Projetos e relatórios de pesquisa em administração. 6. ed. São Paulo: Atlas, 2005.

VERJEIJL, Bart et al. New breakthroughs in computational law - Code X Future Law Conference. Stanford University. 
internet:<https://www.youtube.com/watch?V=efr9VctcMe8: Acesso em: 25 de outubro de 2019.

Voogt, J., \& Roblin, N. P. (2012). A comparative analysis of international frameworks for 21st century competences: Implications for national curriculum policies. Journal of Curriculum Studies, 44(3), 299-321.

WGSN Linkedln. Tech is human, 2019. Disponível na Internet: <https://www.futurodotrabalho.co/> Acesso em: 16 set. 2019.

WGSN Linkedln. Tech is human, 2019. Disponível na Internet: $<$ https://www.futurodotrabalho.co/educacao $>$ Acesso em: 16 set. 2019.

WGSN Linkedln. Tech is human, 2019. Disponível na Internet: <https://www.futurodotrabalho.co/recomendacoes> Acesso em: 16 set. 2019.

WORLD ECONOMIC FORUM. New vision for education - Unlocking the potential of technology, 2015.2 Disponível em:<http://www3.weforum.org/docs/WEFUSA_NewVisionforEducation_Report2015.pdf> . Acesso em: 30 de setembro de 2019. 


\section{Anexos}

\subsection{Roteiro de entrevistas}

1. Como você analisa o mercado de trabalho hoje?

2. Você sabe o que é indústria 4.0? o que é, na sua opinião?

3. Qual a sua opinião a respeito dos impactos causados pela Indústria 4.0 no mercado de trabalho?

4. Quais os principais desafios causados pela quarta revolução industrial?

5. E qual a sua percepção a respeito das principais competências requeridas neste novo contexto?

6. Como deve ser a capacitação dos profissionais para as atividades mais complexas para atuarem com esta tecnologia 4.0?

7. Você se sente preparado? Como você se prepara/ou? Além da graduação, o que mais gostaria de fazer para se tornar um profissional competitivo?

8. Como você vê o mercado de trabalho daqui a 10 anos?

9. E que competências serão necessárias daqui a 10 anos, na sua opinião?

10. E como as pessoas devem se desenvolver? 
11. Há algo mais que gostaria de acrescentar? 